\title{
Curcumin-induced inhibition of cellular reactive oxygen species generation: Novel therapeutic implications
}

\author{
M BALASUbramanyam*, A AdAiKala Koteswari, R SAMPATH Kumar, S FinNy MONickARAJ, \\ J UMA MAHESWARI and V MOHAN \\ Division of Cell and Molecular Biology, Madras Diabetes Research Foundation, \\ 4 Conran Smith Road, Gopalapuram, Chennai 600 086, India \\ Corresponding author (Fax, 91-44-2835 0935; Email,drbalu@mdrf.org)
}

\begin{abstract}
There is evidence for increased levels of circulating reactive oxygen species (ROS) in diabetics, as indirectly inferred by the findings of increased lipid peroxidation and decreased antioxidant status. Direct measurements of intracellular generation of ROS using fluorescent dyes also demonstrate an association of oxidative stress with diabetes. Although phenolic compounds attenuate oxidative stress-related tissue damage, there are concerns over toxicity of synthetic phenolic antioxidants and this has considerably stimulated interest in investigating the role of natural phenolics in medicinal applications. Curcumin (the primary active principle in turmeric, Curcuma longa Linn.) has been claimed to represent a potential antioxidant and antiinflammatory agent with phytonutrient and bioprotective properties. However there are lack of molecular studies to demonstrate its cellular action and potential molecular targets. In this study the antioxidant effect of curcumin as a function of changes in cellular ROS generation was tested. Our results clearly demonstrate that curcumin abolished both phorbol-12 myristate-13 acetate (PMA) and thapsigargin-induced ROS generation in cells from control and diabetic subjects. The pattern of these ROS inhibitory effects as a function of dose-dependency suggests that curcumin mechanistically interferes with protein kinase C (PKC) and calcium regulation. Simultaneous measurements of ROS and $\mathrm{Ca}^{2+}$ influx suggest that a rise in cytosolic $\mathrm{Ca}^{2+}$ may be a trigger for increased ROS generation. We suggest that the antioxidant and antiangeogenic actions of curcumin, as a mechanism of inhibition of $\mathrm{Ca}^{2+}$ entry and PKC activity, should be further exploited to develop suitable and novel drugs for the treatment of diabetic retinopathy and other diabetic complications.
\end{abstract}

[Balasubramanyam M, Koteswari A A, Kumar R S, Monickaraj S F, Maheswari J U and Mohan V 2003 Curcumin-induced inhibition of cellular reactive oxygen species generation: Novel therapeutic implications; J. Biosci. 28 715-721]

\section{Introduction}

Increasing evidence in both experimental and clinical studies suggests that oxidative stress plays a major role in the pathogenesis of diabetes mellitus (Mercuri et al 2000; Brownlee 2001; Rosen et al 2001; Bonnefont-Rousselot 2002; Ceriello 2003). Free radicals are formed disproportionately in diabetes by glucose oxidation, non-enzymatic glycation of proteins, and the subsequent oxidative degradation of glycated proteins. Abnormally high levels of free radicals and the simultaneous decline of antioxidant defense mechanisms can lead to damage of cellular organelles and enzymes, increased lipid peroxidation, and development of insulin resistance. Therefore, oxidative stress is considered a common endpoint of chronic diseases like diabetes (Baynes 1991) and is often characterized by

Keywords. Curcumin; diabetes; oxidative stress; reactive oxygen species

Abbreviations used: DCF, 2',7'-dichlorofluorescein; HBS, HEPES buffered saline; IP3, inositol-triphosphate; PKC, protein kinase C; PMA, phorbol-12 myristate-13 acetate; ROS, reactive oxygen species; SERCA, sarco/endoplasmic reticulum Ca ${ }^{2+}$ ATPase; Tg, thapsigargin. 
an increase in the steady state concentration of reactive oxygen species (ROS), such as $\mathrm{H}_{2} \mathrm{O}_{2}$, lipid peroxides, superoxide and hypochlorous acid. Oxidative stress can modulate a wide variety of biological processes by coupling signals at the cell surface with changes in gene expression, suggesting that multiple signalling pathways are involved. Indeed, ROS may be defined as true secondmessenger molecules that regulate various signal transduction cascades upstream of nuclear transcription factors, including modulation of $\mathrm{Ca}^{2+}$ signalling, protein kinase and protein phosphatase pathways (Sundaresan et al 1995; Palmer and Paulson 1997). Therefore, it is important to explore the relationship between free radicals, diabetes, and its complications, and to elucidate the mechanisms by which increased oxidative stress accelerates the development of diabetic complications. These efforts will ultimately expand and increase our treatment options.

There is a need for screening of herbal medicines with special reference to diabetes and its complications (Balasubramanyam and Mohan 2002). The significance of Curcuma longa Linn. (turmeric) in health and nutrition has changed considerably since the discovery of the antioxidant properties of naturally occurring phenolic compounds. The dried rhizome of $C$. longa (used as a spice, food preservative and a colouring agent) is a rich source of beneficial phenolic compounds; the curcuminoids (Srinivasan 1953). Curcuminoids are a group of phenolics present in turmeric. These curcuminoids are chemically related to its principal ingredient; the curcumin. Three main curcuminoids were isolated from turmeric: namely; curcumin (C), demethoxycurcumin (DMC) and bisdemethoxycurcumin (BDMC). In this study we have tested the antioxidant effect of curcumin as a function of changes in cellular ROS generation and explored its novel mechanisms of protection against oxidative stress.

\section{Materials and methods}

\subsection{Study subjects}

All study subjects were recruited from M V Diabetes Specialities Centre (MVDSC) at Gopalapuram, Chennai. Additionally, healthy volunteers were also recruited for blood sampling for the standardization of various methodologies related to cellular approaches. Statistical data analysis was performed using PC-compatible SPSS package.

\subsection{Lymphocyte isolation}

Freshly collected blood was carefully layered on top of Histopaque (1077) or Lymphoprep density gradient solu- tion and centrifuged at $1600 \mathrm{rpm}$ for $30 \mathrm{~min}$. The buffy coat interface that represents lymphocytes was aspirated and suspended in $1 \mathrm{ml}$ HEPES buffered saline (HBS, $\mathrm{pH} 7.4$ ) containing $140 \mathrm{mM} \mathrm{NaCl}, 5 \mathrm{mM} \mathrm{KCl}, 10 \mathrm{mM}$ HEPES, $10 \mathrm{mM}$ glucose, $1 \mathrm{mM} \mathrm{CaCl} 2$ and $1 \mathrm{mM} \mathrm{MgCl}_{2}$. Curcumin, thapsigargin, dicholorofluorescein diacetate, Fura2-AM and phorbol-12 myrsitate-13 acetate (PMA) were obtained from Sigma-Aldrich Co., USA. All other reagents used were of analytical grade.

\subsection{Determination of intracellular ROS production}

To measure intracellular ROS production, cells were loaded with $10 \mu \mathrm{M}$ dichlorofluorescein diacetate (DCFHDA) for $45 \mathrm{~min}$. ROS levels were measured (using Fluoromax-3 spectrofluorimeter with an excitation set at $485 \mathrm{~nm}$ and emission at $530 \mathrm{~nm}$ ) as a change in the fluorescence because of the conversion of non-fluorescent dichlorofluorescein diacetate to the highly fluorescent compound 2',7'-dichlorofluorescein (DCF) in the cells. Aliquots of cell suspension $(100 \mu \mathrm{l})$ were incubated for 10 min with curcumin and resuspended in HBS prior to each experiment. This potentially eliminated the interference of curcumin in fluorescence assays.

\subsection{Measurement of $\mathrm{Ca}^{2+}$ influx}

Lymphocyte suspension was incubated with $5 \mu \mathrm{M}$ Fura-2 $\mathrm{AM}$ for a minimum of $30 \mathrm{~min}$ at $37^{\circ} \mathrm{C}$ and delivered as $100 \mu \mathrm{l}$ aliquots. Prior to each experiment, cells were centrifuged for 5-10 s at room temperature, resuspended in $100 \mu \mathrm{l}$ of HBS, and injected into cuvettes containing $3 \mathrm{ml}$ of assay buffer. $\mathrm{Ca}^{2+}$ influx was measured using a methodology of $\mathrm{Mn}^{2+}$ quenching of intracellular fura (Balasubramanyam et al 1993). Here, $\mathrm{Mn}^{2+}$ is used as a surrogate marker of measuring $\mathrm{Ca}^{2+}$ entry. When measured at an isobestic wavelength of $360 \mathrm{~nm}$, the $\mathrm{Mn}^{2+}$ quenching of intracellular fura is a relative measurement of $\mathrm{Ca}^{2+}$ entry into the cells.

\section{Results}

Curcumin-induced cellular changes were studied using two agents viz., thapsigargin (Tg) and PMA which specifically interfere with calcium and protein kinase $\mathrm{C}$ (PKC) metabolism, respectively, and increase cellular ROS production. Tg is a pharmacological specific inhibitor of sarcoplasmic endoplasmic reticular calcium (SERCA). ATPases and cells treated with $\mathrm{Tg}$ exhibit depletion of intracellular $\mathrm{Ca}^{2+}$ stores and subsequent rise in cytosolic $\mathrm{Ca}^{2+}$, as a function of store-operated $\mathrm{Ca}^{2+}$ influx (Thastrup 
et al 1990; Balasubramanyam et al 1993). PMA is a common activator of cellular PKC isozymes (Ohno and Nishizuka 2002). Figure 1 shows the Tg-induced ROS generation in cells from control and diabetic subjects, with a general trend of increased ROS in diabetic patients. In cells pretreated with curcumin $(100 \mu \mathrm{M})$, there was a total absence of $\mathrm{Tg}$-induced ROS generation. The extent of curcumin inhibition of Tg-induced ROS generation was almost same in cells from control $(88 \% \pm 4.5)$ and diabetic $(92 \% \pm 1.7)$ subjects. When lymphocytes were treated with PMA - a PKC activator - PMA induced increased levels of ROS generation (figure 2). In general, PMA-induced ROS generation was less in cells from diabetes patients compared to control subjects. However, the extent of curcumin inhibition of PMA-induced ROS generation was almost the same in cells from control $(91 \% \pm 3 \cdot 6)$ and diabetic $(88 \% \pm 4 \cdot 34)$ subjects. To prove that the effect of curcumin was not non-specific but rather a mechanistic biological phenomenon, dose-dependent effects of curcumin were tested on both $\mathrm{Tg}$-induced and PMA-induced ROS generation. Curcumin dose-dependently $(0 \cdot 1 \mu \mathrm{M}$ to $100 \mu \mathrm{M})$ inhibited PMA-induced cytosolic ROS levels (figure 3). Similar inhibitory effects of curcumin $(0.3 \mu \mathrm{M}$ to $100 \mu \mathrm{M})$ were also observed on $\mathrm{Tg}$ - induced ROS generation (data not shown). These results demonstrate specific biological effects of curcumin on important messenger molecules, such as cytosolic calcium and PKC.

Earlier studies indicated that Tg-induced cellular $\mathrm{Ca}^{2+}$ entry was higher in cells from diabetes patients (Balasubramanyam et al 2001), and an increase in cytosolic $\mathrm{Ca}^{2+}$ via store-operated $\mathrm{Ca}^{2+}$ entry is a prerequisite for increased intracellular ROS generation (Balasubramanyam et al 2002). If there is an existence of a cross-talk signalling of increased ROS and cytosolic calcium, it should be possible to demonstrate in an experiment where simultaneously ROS and $\mathrm{Ca}^{2+}$ entry are measured. As shown in figure 4, Mn quenching of intracellular fura is a reliable measure of $\mathrm{Ca}^{2+}$ entering into the cells (dotted lines) and DCF-fluorescence is a reliable measure of intracellular ROS generation, both events initiated by Tg. This methodology clearly indicates that an increase in $\mathrm{Ca}^{2+}$ rise in the cell is a trigger for increased ROS generation. Interestingly, curcumin inhibits both Tg-induced $\mathrm{Ca}^{2+}$ entry and ROS generation, suggesting that $\mathrm{Ca}^{2+}$ entry inhibition might be one of the mechanisms by which curcumin exerts its antioxidant effect and inhibits ROS generation.
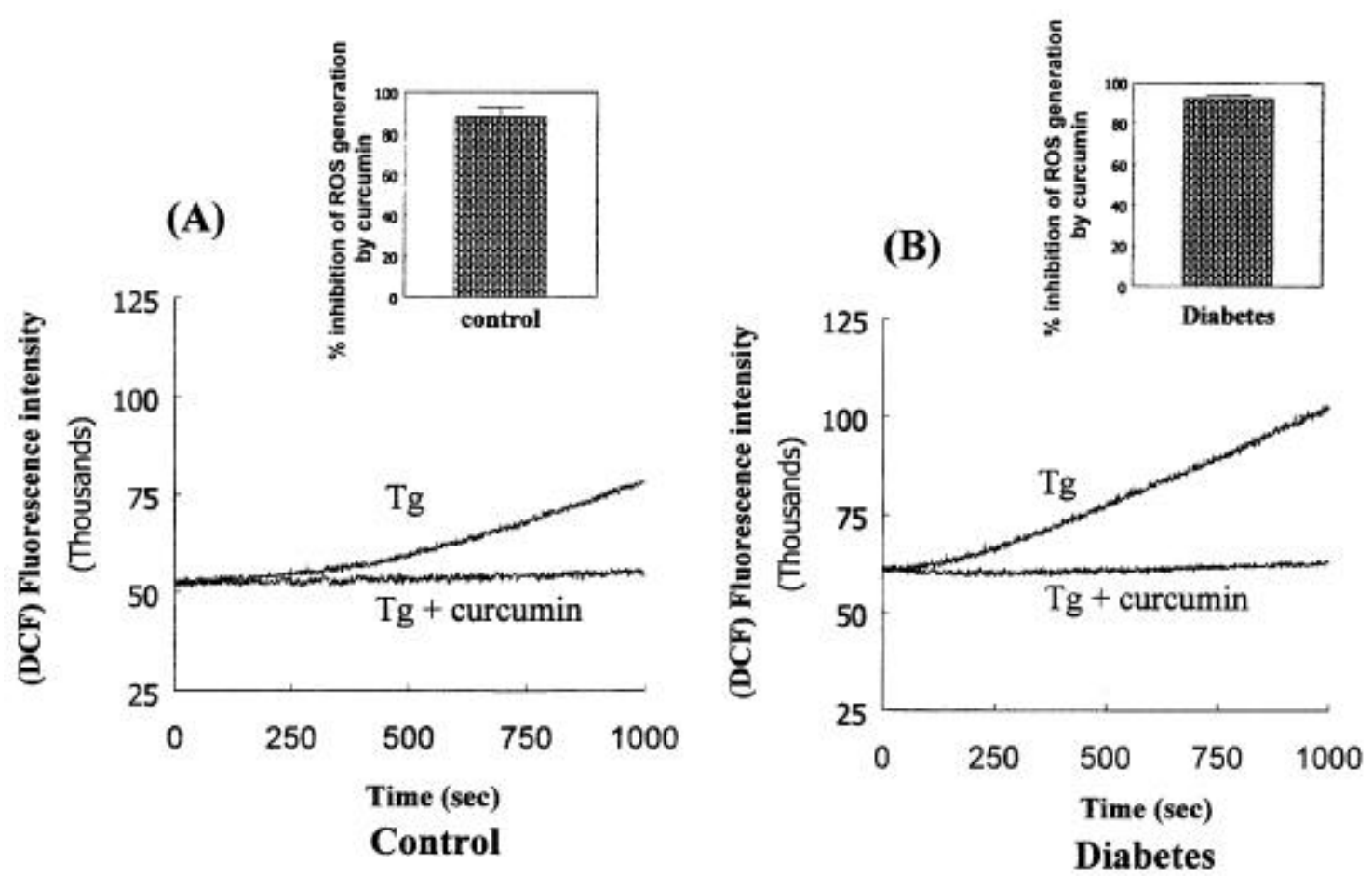

Figure 1. Curcumin inhibition of Tg-induced ROS generation in cells from control (A) and type 2 diabetes subjects (B). Freshly isolated lymphocytes were resuspended in HBS buffer and loaded with $10 \mu \mathrm{M}$ DCF for $45 \mathrm{~min}$. At time ' 0 ' thapsigargin $(100 \mathrm{nM})$ was added and increase in DCF fluorescence was monitored for $1000 \mathrm{~s}$, with and without curcumin $(100 \mu \mathrm{M})$. Insets indicate percent inhibition of ROS generation by curcumin. Each bar diagram represents cumulative data obtained from 6 to 10 separate experiments. 

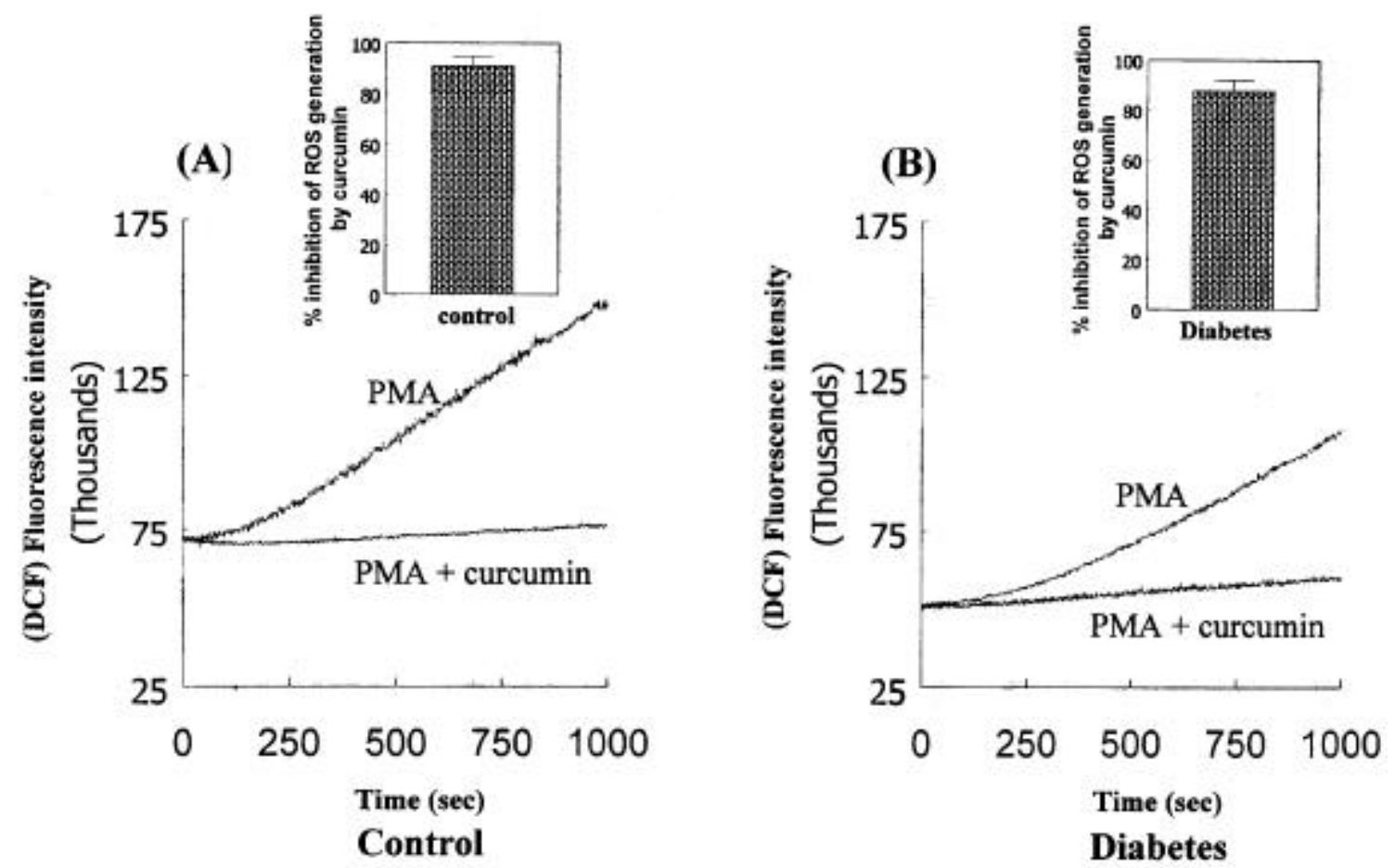

Figure 2. Curcumin inhibition of PMA-induced ROS generation in cells from control (A) and type 2 diabetes subjects (B). Experimental maneuvers were same as in figure 1.

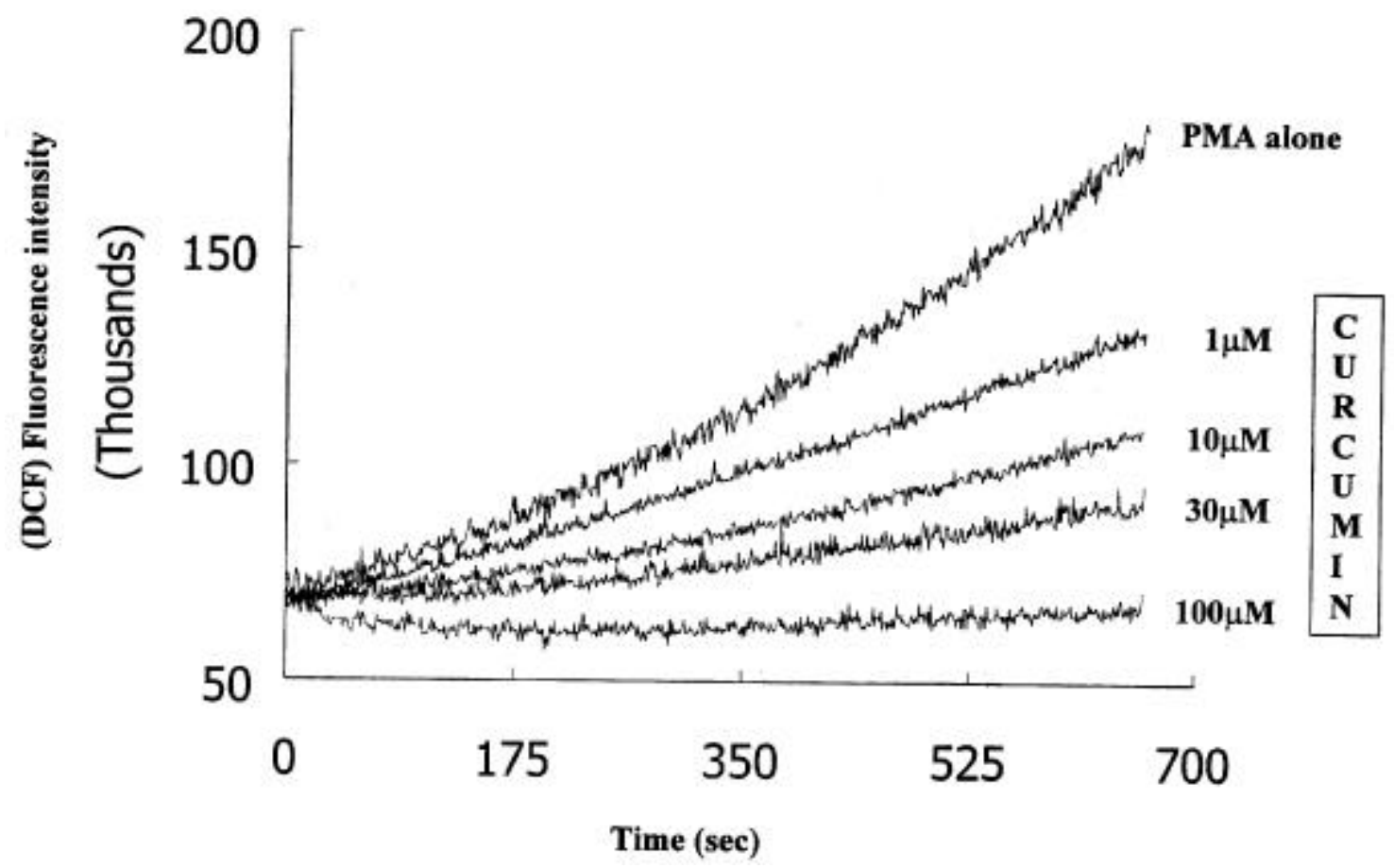

Figure 3. Curcumin dose-dependently inhibits PMA-induced intracellular ROS generation. Increases in DCF fluorescence after the addition of PMA were monitored in the absence and presence $(1 \mu \mathrm{M}$ to $100 \mu \mathrm{M})$ of curcumin. Representative traces of 4 separate dose-dependency experiments. 


\section{Discussion}

Earlier studies have shown that curcumin can affect a number of cellular processes including activation of apoptosis in Jurkat T cells (Piwocka et al 1999), inhibition of platelet aggregation (Shah et al 1999; Srivastava et al 1995), and inhibition of inflammatory cytokine production in macrophages (Abe et al 1999). Curcumin has also been shown to affect the activity of a number of key enzymes such as cyclooxygenase (Zhang et al 1999), PKC (Liu et al 1993), protein tyrosine kinases (Chen and Huang 1998) and a $\mathrm{Ca}^{2+}$-dependent endonuclease (Chen et al 1996). Many of these processes/enzymes were known to be regulated by $\mathrm{Ca}^{2+}$. Cytosolic calcium is tightly con- trolled. The sarco/endoplasmic reticulum $\mathrm{Ca}^{2+}$ ATPase (SERCA) is one of the major mechanisms by which the low levels of cytosolic calcium $(\sim 100 \mathrm{nM})$ are maintained within cells. Interestingly, it has been shown that all subtypes of SERCA are inhibited to a similar degree by curcumin (Bilmen et al 2001). In our study, curcumin inhibits Tg-induced ROS production and $\mathrm{Ca}^{2+}$ entry. The likely mechanisms are: (i) curcumin apart from its effects on SERCA may also inhibit inositol-triphosphate(IP3)sensitive $\mathrm{Ca}^{2+}$ channel (Dyer et al 2002) and thereby break the coupling of IP3-sensitive $\mathrm{Ca}^{2+}$ store and $\mathrm{Ca}^{2+}$ entry; and (ii) curcumin may inhibit cytosolic signals (enzymes or other signalling molecules) that are responsible for $\mathrm{Ca}^{2+}$ entry into the cells.

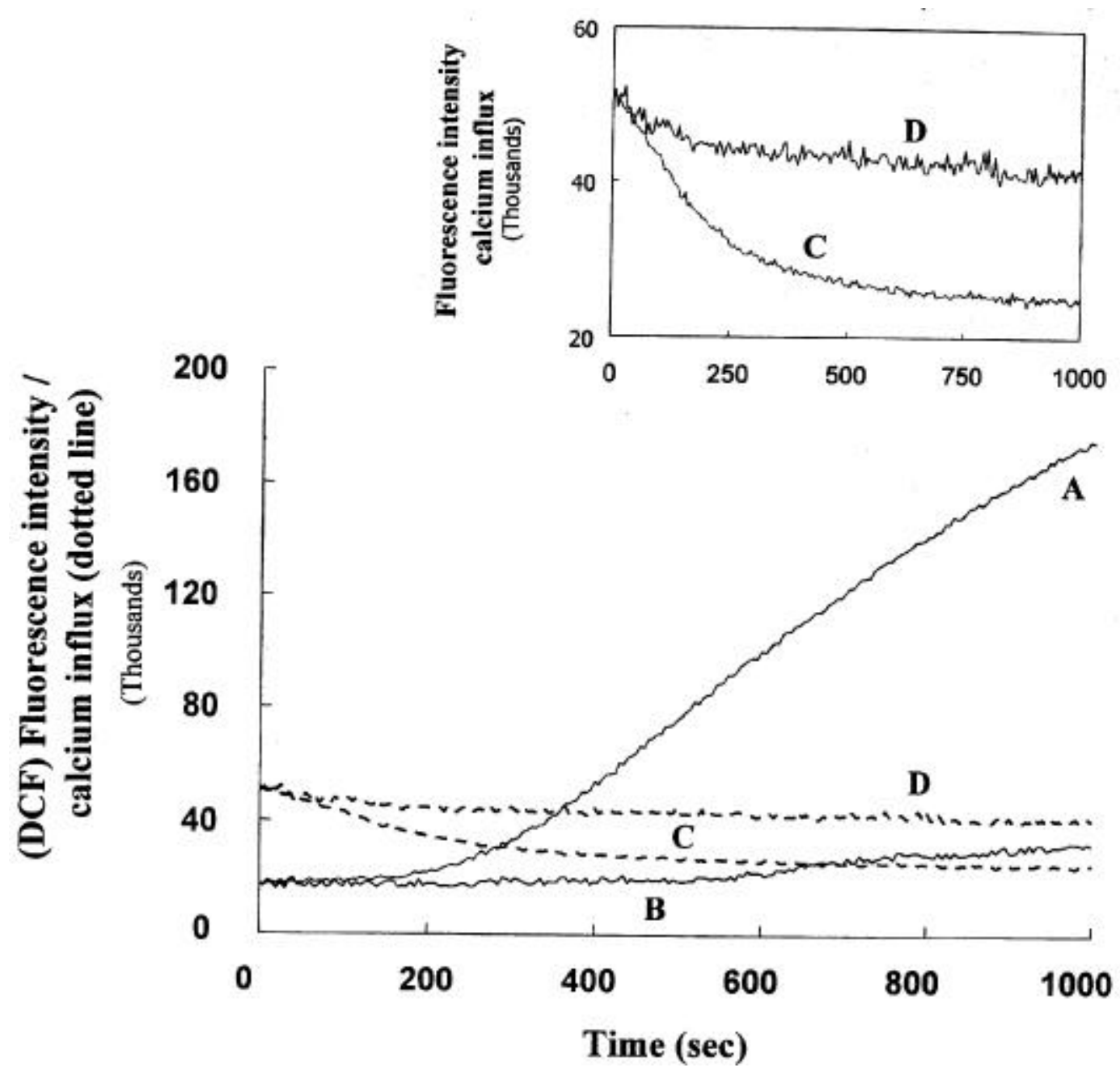

Figure 4. Methodology for simultaneous measurement of ROS generation and $\mathrm{Ca}^{2+}$ influx. Cells were co-loaded with both DCF and Fura and changes in respective fluorescence intensities were monitored using multiwavelength parameters in a Fluoromax-3 spectrofluorimeter. Solid lines represent increases in Tg-induced ROS generation (A) and its inhibition by curcumin (B). Dotted lines represent Tg-induced $\mathrm{Mn}^{2+}$ quenching (C) of intracellular fura (a surrogate measure of $\mathrm{Ca}^{2+}$ influx) and its inhibition by curcumin (D). Representative traces of 4 separate experiments. Inset: Traces (C) and (D) were separately illustrated to show the extent of Tg-induced $\mathrm{Ca}^{2+}$ influx and its inhibition by curcumin. 
Curcumin inhibition of PMA-induced ROS generation suggests that curcumin has an inhibitory action on PKC activity. It is now recognized that low levels of oxidants can modify cell-signalling proteins and that these modifications have functional consequences (Lee et al 1989). For example, PKC is a logical candidate for redox modification by oxidants and antioxidants that may in part determine their cancer-promoting and anticancer activities, respectively. PKC contains unique structural features that are susceptible to oxidative modification. The N-terminal regulatory domain contains zinc-binding, cysteinerich motifs that are readily oxidized by peroxide. When oxidized, the auto inhibitory function of the regulatory domain is compromised and, consequently, cellular PKC activity is stimulated. The C-terminal catalytic domain contains several reactive cysteines that are targets for various chemopreventive antioxidants (such as selenocompounds), polyphenolic agents (such as curcumin), and vitamin E analogues (Gopalakrishna and Jaken 2000). Modification of these cysteines decreases cellular PKC activity. Thus the two domains of $\mathrm{PKC}$ respond differently to two different types of agents. Oxidants selectively react with the regulatory domain, stimulate cellular PKC, and act as a signal for tumour promotion and cell growth. In contrast, antioxidant chemo preventive agents react with the catalytic domain, inhibit cellular PKC activity, and, thus, interfere with the PKC-overactivation-driven pathological processes.

Curcumin inhibition of PKC may impose several therapeutic implications in diabetes, particularly in case of diabetic retinopathy. Increased PKC activation has been demonstrated in experimental diabetic retinopathy studies (Kowluru 2001) and several PKC inhibitors (PKC $\beta I I)$ are being tested for their efficacy and safety in clinical trials (Frank 2002). Specifically, in diabetic retinopathy, both the genesis and the advanced stage of proliferative diabetic retinopathy (PDR) have been hypothesized to be a result of increased oxidative species (Armstrong et al 1998) or to be associated with ischemia-perfusion injury at the boundaries of perfused and nonperfused retina, which leads to both increased oxidative species and neovascularization. Since curcumin is also an angiogenesis inhibitor and inhibits multistep progression of angiogenesis in vitro and in vivo, one cannot underestimate its therapeutic potentials. It appears that the pleiotropic effects of curcumin are at least partly due to inhibition of the transcription factors NF-kappa B and AP-1 (Bierhaus et al 1997). Okamoto et al (2002) reported that curcumin prevents the AGE-induced increase in NF- $\mathrm{KB}$ and AP-1 activity, vascular endothelial growth-factor (VEGF) mRNA up-regulation and the resultant increase in DNA synthesis in microvascular endothelial cells. Any drug with multiple actions, such as antioxidant and antiangiogenic effects, is an ideal formulation in the treatment of diabetic retinopathy.
Our results demonstrate that antioxidant effects of curcumin involve, among other mechanisms, the inhibition of $\mathrm{Ca}^{2+}$ influx and PKC. This information extends the known cellular actions of curcumin to potentially multiple therapeutic targets. Pharmacologically, curcumin is reported as safe (Aggarwal et al 2003). A phase-one human trial with 25 subjects using up to $8000 \mathrm{mg}$ of curcumin per day for 3 months found no toxicity from curcumin (Cheng et al 2001). Five other human trials using 1125$2500 \mathrm{mg}$ of curcumin per day also showed no toxicity (Chainani-Wu 2003). Xu et al (2003) reported that curcumin inhibited the proliferation of activated hepatic stellate cells and this thas been mediated by curcumin induction of the gene expression of PPAR $\gamma$ and PPAR $\gamma$ activation. The PPAR $\gamma$ agonists, thioazolidenediones (which are primarily antidiabetic agents) are claimed to offer multiple therapeutic benefits via their beneficial vascular and anti-inflammatory effects (Martens et al 2002). In this context, curcumin on further scientific validation appears to have multiple potential in the treatment regimen of diabetes and its complications, which constitutes a collection of metabolic, vascular and inflammatory defects.

\section{Acknowledgements}

This work was supported by a research grant from the Department of Science and Technology, New Delhi.

\section{References}

Abe Y, Hashimoto S and Horie T 1999 Curcumin inhibition of inflammatory cytokine production by human peripheral blood monocytes and alveolar macrophages; Pharmacol. Res. 39 $41-47$.

Aggarwal B B, Kumar A and Bharti A C 2003 Anticancer potential of curcumin: preclinical and clinical studies; Anticancer Res. 23 363-398

Armstrong D, Ueda T, Aljada A, Browne R, Fukuda S, Spengler R, Chou R, Hartnett M, Buch P, Dandona P, Sasisekharan R and Dorey C K 1998 Lipid hydroperoxide stimulates retinal neovascularisation in rabbit retina through expression of tumor necrosis factor-alpha, vascular endothelial growth factor and platelet-derived growth factor; Angiogenesis 2 93-104

Balasubramanyam M, Kimura M, Aviv A and Gardner J P 1993 Kinetics of calcium transport across the lymphocyte plasma membrane; Am. J. Physiol. 265 C321-C327

Balasubramanyam M, Balaji A, Subashini B and Mohan V 2001 Evidence for mechanistic alterations of $\mathrm{Ca}^{2+}$ homeostasis in type 2 diabetes mellitus; Int. J. Exp. Diabetes Res. 1 $275-287$

Balasubramanyam M and Mohan V 2002 The need for high throughput screening of herbal medicine with special reference to diabetes mellitus; in Biodiversity (monitoring, management, conservation and enhancement) (eds) R Ramamurthi and G Bali (New Delhi: APH Publishing Corp.) pp 57-74

Balasubramanyam M, Premanand C, Sampathkumar R and Mohan V 2002 Rosiglitazone and troglitazone protect against 
Oxidative Stress: Possible role of Store-Operated $\mathrm{Ca}^{2+}$ Fluxes; Diabetes (Suppl. 2) 54 A449

Baynes J W 1991 Role of oxidative stress in development of complications in diabetes; Diabetes 40 405-412

Bierhaus A, Zhang Y, Quehenberger P, Luther T, Haase M, Muller M, Mackman N, Ziegler R and Nawroth P P 1997 The dietary pigment curcumin reduces endothelial tissue factor gene expression by inhibiting binding of AP-1 to the DNA and activation of NF-kappa B; Thromb. Haemost. 77772 782

Bilmen J G, Khan S Z, Javed M H and Michelangeli F 2001 Inhibition of SERCA $\mathrm{Ca}^{2+}$ pumps by curcumin; Eur. J. Biochem. 268 6318-6327

Bonnefont-Rousselot D 2002 Glucose and reactive oxygen species; Curr. Opin. Clin. Nutr. Metab. Care 5 561-568

Brownlee M 2001 Biochemistry and molecular cell biology of diabetic complications; Nature (London) 414 813-820

Ceriello A 2003 New insights on oxidative stress and diabetic complications may lead to a "Causal" antioxidant therapy; Diabetes Care 26 1589-1596

Chainani-Wu N 2003 Safety and anti-inflammatory activity of curcumin: A component of turmeric (Curcuma longa); $J$. Altern. Complement. Med. 9 161-168

Chen Y C, Kuo T C, Lin-Shiau S Y and Lin J K 1996 Induction of HSP70 gene expression by modulation of $\mathrm{Ca}^{2+}$ ion and cellular p53 protein by curcumin in colorectal carcinoma cells; Mol. Carcinog. 17 224-234

Chen H W and Huang H C 1998 Effect of curcumin on cell cycle progression and apoptosis in vascular smooth muscle cells; Br. J. Pharmacol. 124 1029-1040

Cheng A L, Hsu C H, Lin J K, Hsu M M, Ho Y F, Shen T S, Ko J Y, Lin J T, Lin B R, Ming-Shiang W, Yu H S, Jee S H, Chen G S, Chen T M, Chen C A, Lai M K, Pu Y S, Pan M H, Wang Y J, Tsai C C and Hsieh C Y 2001 Phase I clinical trial of curcumin, a chemopreventive agent, in patients with high-risk or pre-malignant lesions; Anticancer Res. 212895 2900

Dyer J L, Khan S Z, Bilmen J G, Hawtin S R, Wheatley M, Javed M U and Michelangeli F 2002 Curcumin: a new cellpermeant inhibitor of the inositol 1,4,5-trisphosphate receptor; Cell Calcium 31 45-52

Frank R N 2002 Potential new medical therapies for Diabetic Retinopathy: Protein Kinase C inhibitors; Am. J. Ophthalmol. 133 693-698

Gopalakrishna R and Jaken S 2000 Protein Kinase C signalling and oxidative stress; Free Radic. Biol. Med. 28 1349-1361

Kowluru R A 2001 Diabetes-induced elevations in retinal oxidative stress, protein kinase $\mathrm{C}$ and nitric oxide are interrelated; Acta Diabetol. 38 179-185

Lee T S, Saltsman K A, Ohashi H and King G L 1989 Activation of protein kinase $\mathrm{C}$ by elevation of glucose concentration: Proposal for a mechanism in the development of diabetic vascular complications; Proc. Natl. Acad. Sci. USA 86 51415145

Liu J Y, Lin S J and Lin J K 1993 Inhibitory effects of curcumin on protein kinase $\mathrm{C}$ activity induced by 12 -O-tetradecanoyl- phorbol-13-acetate in NIH 3T3 cells; Carcinogenesis 14 857861

Martens F M, Visseren F L, Lemay J, de Koning E J and Rabelink T J 2002 Metabolic and additional vascular effects of thioazolidinediones; Drugs 62 1463-1480

Mercuri F, Quagliaro L and Ceriello A 2000 Oxidative stress evaluation in diabetes; Diabetes Technol. Ther. 2 589-600

Ohno S and Nishizuka Y 2002 Protein kinase C Isotypes and their specific functions: Prologue; J. Biochem. 132 509-511

Okamoto T, Yamagishi S, Inagaki Y, Amano S, Koga K, Abe R, Takeuchi M, Ohno S, Yoshimura A and Makita Z 2002 Angiogenesis induced by advanced glycation end products and its prevention by cerivastin; FASEB J. 16 1928-1930

Palmer H J and Paulson K E 1997 Reactive oxygen species and antioxidants in signal Transduction and gene expression; Nutr. Rev. 55 353-361

Piwocka K, Zablocki K, Wieckowski M R, Skierski J, Feiga I, Szopa J, Derla N, Wojtczak L and Sikora E 1999 A novel apoptosis-like pathway, independent of mitochondria and caspases, induced by curcumin in human lymphoblastoid $\mathrm{T}$ (Jurkat) cells; Exp. Cell. Res. 249 299-307

Rosen P, Nawroth P P, King G, Moller W, Tritschler H-J and Packer L 2001 The role of oxidative stress in the onset and progression of diabetes and its complications: a summary of a Congress Series sponsored by UNESCO-MCBN, the American Diabetes Association and the German Diabetes Society; Diabetes Metab. Res. Rev. 17 189-212

Shah B H, Nawaz Z, Pertani S A, Roomi A, Mahmood H, Saeed S A and Gilani A H 1999 Inhibitory effect of curcumin, a food spice from turmeric, on platelet-activating factorand arachidonic acid-mediated platelet aggregation through inhibition of thromboxane formation and $\mathrm{Ca}^{2+}$ signalling; Biochem. Pharmacol. 58 1167-1172

Srinivasan K R 1953 Chromatographic study of the curcuminoids in Curcuma longa; J. Pharma. Pharmacol. 5448

Srivastava K C, Bordia A and Verma S K 1995 Curcumin, a major component of food spice turmeric (Curcuma longa) inhibits aggregation and alters eicosanoid metabolism in human blood platelets; Protaglandins Leukot. Essent. Fatty Acids $\mathbf{5 2}$ 223-227

Sundaresan M, Yu Z X, Ferrans V J, Irani K and Finkel T 1995 Requirements for generation of $\mathrm{H}_{2} \mathrm{O}_{2}$ for PDGF signal transduction; Science 270 296-299

Thastrup O, Cullen P J, Droback B K, Humley M R and Dawson A P 1990 Thapsigargin, a tumor promoter, discharges intracellular $\mathrm{Ca}^{2+}$ stores by specific inhibition of the endoplasmic reticulum $\mathrm{Ca}^{2+}$-ATPase; Proc. Natl. Acad. Sci. USA 872466 2470

$\mathrm{Xu} \mathrm{J}, \mathrm{Fu} \mathrm{Y}$ and Chen A 2003 Activation of peroxisome proliferator-activated receptor-(gamma) contributes to the inhibitory effects of curcumin on rat hepatic stellate cell growth; Am. J. Physiol. 285 G20-G30

Zhang F, Altorki N K, Mestre J R, Subbaramaiah K and Dannenberg A J 1999 Curcumin inhibits cyclooxygenase-2 transrcription in bile acid- and phorbol ester-treated human gastrointestinal epithelial cells; Carcinogenesis 20 445-451

MS received 27 May 2003; accepted 30 September 2003

Corresponding editor: VIDYANAND NANJUNDIAH

J. Biosci. | Vol. 28 | No. 6 | December 2003 